\title{
The impact of sparse millet crops on evaporation from soil in semi-arid Niger
}

\author{
Carl C. Daamen ${ }^{\text {a,* }}$, L.P. Simmonds ${ }^{\text {a }}$, M.V.K. Sivakumar ${ }^{b}$ \\ ${ }^{a}$ Department of Soil Science, University of Reading, Whiteknights, P.O. Box 233, Reading RG6 2DW, UK \\ ${ }^{\mathrm{b}}$ ICRISAT Sahelian Center, B.P. 12404, Niamey, Niger
}

Accepted 3 November 1994

\begin{abstract}
Direct evaporation from soil is an important component of crop water balances in semi-arid environments. The effects of a crop and of crop management on this water loss from the soil have been estimated in the past using combinations of field measurement and simple models, but there are inconsistencies in the conclusions reached.

This paper presents data from water balance studies on millet crops in Niger during the 1991 and 1993 seasons. Evaporation from soil $\left(E_{\mathrm{s}}\right)$ was measured under two contrasting cropping intensities in both years using the microlysimeter method. Small seasonal reductions in $E_{\mathrm{s}}$ from the higher intensity crop were recorded (12\% and $16 \%$ in 1991 and 1993, respectively). Significant reductions in daily $E_{\mathrm{s}}$ were: (1) nearly all recorded within a limited period in the season when there were large differences in transpiring leaf area; (2) recorded for both high ( $\left.>=2 \mathrm{~mm} \mathrm{day}^{-1}\right)$ and low $(<0.8$ $m m$ day $^{-1}$ ) values of $E_{\mathrm{s}}$. These data indicate that soil drying by root water uptake contributed to the reduction of $E_{\mathrm{s}}$. Increased shading of the soil by the crop canopy does not result in a proportional reduction of $E_{\mathrm{s}}$.

Two simple models for estimating $E_{\mathrm{s}}$ beneath crops (Ritchie, 1972; Cooper et al., 1983) are compared with field data and an improvement to the Ritchie model is suggested. Two new parameters are introduced to estimate the relative importance of (1) the atmospheric vapour pressure deficit to potential evaporation and (2) root water uptake to soil drying. The brief description of environment and crop included in the new approach allows identification of the environments in which there is scope for substantial reduction in $E_{\mathrm{s}}$ through crop management.
\end{abstract}

Keywords: Evaporation; Crop water balance; Pearl millet; Soil evaporation; Model; Microlysimeters

\section{Introduction}

Evaporation from the soil surface $\left(E_{\mathrm{s}}\right)$ can be a major component of crop and soil water balance. In semi-arid environments, some estimates of seasonal $E_{\mathrm{s}}$ beneath annual crops are

*Corresponding author. Tel. + 441734318911 , Fax. + 441734 316660, Email. c.c.daamen@reading.ac.uk. 
in excess of 50\% of seasonal rainfall (Allen, 1990; Papendick and Campbell, 1990; Pilbeam et al., 1995). If this large proportion of rainfall $\left(E_{\mathrm{s}}\right)$ could be decreased and used (at least in part) as transpiration from a crop, an increase in crop yield and seasonal water use efficiency would be expected (Cooper et al., 1987). The potential benefit of reducing evaporation from the soil surface has long been recognised (Lemon, 1956; Penman, 1941). Some success in achieving a reduction in $E_{\mathrm{s}}$ with intensified crop management (e.g. narrower row spacing and application of fertilizer) has been attributed to reduced solar radiation penctration to the soil surface beneath a crop canopy (Adams et al., 1976; Cooper et al., 1983). However, two recent studies in dry mediterranean environments (Allen, 1990; Yunusa et al., 1993a) suggest that a reduction in radiation incident at the soil surface has little or no effect on $E_{\mathrm{s}}$. Furthermore, the effect of root water uptake on $E_{\mathrm{s}}$ is beginning to be considered (Allen, 1990).

To assess the value of crop management practices in the reduction of $E_{\mathrm{s}}, E_{\mathrm{s}}$ must be accurately measured or estimated. The microlysimeter method (Boast, 1986) is a popular approach at present, but it is impractical to measure $E_{\mathrm{s}}$ continuously throughout a crop scason becausc frequent replacement of soil cores is required (Daamen et al., 1993) and measurements are invalid if interrupted by rainfall (Allen, 1990). Thus, seasonal estimation of $E_{\mathrm{s}}$ requires application of a model to either supplement direct measurements (Allen, 1990; Yunusa et al., 1993b) or largely replace the need for measurement (e.g. Ritchie, 1972; Cooper et al., 1983).

This paper presents data from water balance studies on pearl millet crops (Pennisetum glaucum (L.) R.Br.) in Niger during the 1991 and 1993 seasons. Evaporation from soil was measured using microlysimeters under two different cropping intensities in both years. Two models for estimating $E_{\mathrm{s}}$ are compared with field data and some components of an improved model are developed. The new modelling approach offers an explanation of the apparent contradiction in the results of previous studies regarding the effectiveness of management practices in modifying crop water use efficiency. This approach is also used to identify the environments in which there is scope for substantial reduction in $E_{\mathrm{s}}$ through crop management.

\subsection{Models of evaporation from soil}

A classical approach to modelling evaporation from an initially wet soil profile begins with the hypothesis that evaporation occurs in two (or three) distinct and consecutive stages (see Hillel, 1980; Hanks and Ashcroft, 1980; Marshall and Holmes, 1988; Jury et al., 1991). In the first stage, evaporation $\left(E_{\mathrm{s}}\right)$ is limited by the movement of water from the soil surface into the atmosphere, and in the second stage, $E_{\mathrm{s}}$ is limited by the movement of water through the soil to the surface. Such approaches are founded on a theoretical solution of water loss from soil which assumes a constant evaporative demand (no diurnal variation) and an initial soil water content that is the same at all depths. Under field conditions, in which there is a large diurnal variation in evaporative demand and often steep gradients in soil water content with depth, this approach may well be inadequate.

Ritchie (1972), used the two-stage evaporation model to estimate daily $E_{\mathrm{s}}$ beneath a developing crop which was not water stressed. Ritchie's approach has been widely adopted in crop water balance studies (e.g. Shouse et al., 1982; Dierckx et al., 1986; Villalobos and 
Fereres, 1990). Beginning with an initially wet condition, Ritchie assumed that the first stage of evaporation continues until a certain volume of water $(U, \mathrm{~mm})$ has been evaporated from the soil. During this stage, evaporation beneath a crop was deemed to occur at a potential rate which is a fraction (equal to the proportion of solar radiation that penetrates to the soil surface) of the potential rate for bare soil. The validity of this assumption is discussed later. The potential evaporation from soil beneath a crop canopy $\left(E_{\mathrm{pc}}, \mathrm{mm}\right)$ was calculated using the leaf area index $(L)$, an extinction coefficient $(K)$ and a "bare soil" potential evaporation $\left(E_{\mathrm{pR}}, \mathrm{mm}\right)$ as:

$$
\begin{aligned}
& E_{\mathrm{pc}}=E_{\mathrm{pR}} \exp (-K L) \\
& E_{\mathrm{pR}}=[\Delta /(\Delta+\gamma)] R_{\mathrm{no}}
\end{aligned}
$$

where $R_{\mathrm{no}}$ is the daily net radiation, $\Delta$ is the slope of saturation vapour pressure vs. temperature curve at mean air temperature, $\gamma$ is the psychometric constant (Ritchie, 1972). A typical value of $K$ for millet in Niger is 0.41 (Wallace et al., 1990). Using this approach the presence of a crop canopy lengthens the first stage of evaporation because evaporation is slower than that from a bare soil. In the second stage, Ritchie's approach assumed a crop has no influence on evaporation from soil. During the second stage, cumulative evaporation $\left(\sum E_{\mathrm{s}, 2}\right)$ was proportional to the square root of time since the start of the second stage $\left(t_{2}\right.$, days) such that:

$$
\sum E_{\mathrm{s}, 2}=\alpha \sqrt{t_{2}}
$$

where $\alpha$ is a constant for a given soil.

It should be noted that a strict system of accounting for water fluxes was adopted by Ritchie (1972). An implicit assumption of this approach is that the soil water content controls the movement of water to the soil surface and this water content is a function of time or $\sum E_{\mathrm{s}}$ only. The effect of root water uptake on soil water content is assumed negligible, although this might be a major loss of water from the surface layers.

The second modelling approach considered here is an empirical model suited to a crop environment in northern Syria (Cooper et al., 1983). No explicit first and second stages are used, although the first day after rain is effectively a first stage. The daily evaporation from soil beneath a canopy is determined by the number of days since rain, $t$, and the crop green area index $G$ as:

$$
E_{\mathrm{s}}=E_{\mathrm{pC}} \frac{\exp (-K G)}{t}
$$

where $E_{\mathrm{pC}}$ is the daily potential evaporation, which was estimated from pan evaporation measurements by Cooper et al. (1983). Both $E_{\mathrm{pC}}$ and $G$ influence the estimate of evaporation throughout the drying cycle. This is in contrast with the approach of Ritchie (1972) in which these factors only influence $E_{\mathrm{s}}$ during the first stage of evaporation. Although Cooper et al. (1983) use $G$ (green area index) and not total leaf area index, their discussion does not indicate that this was intended to account for root water uptake/transpiration in any way: it was only used to make allowance for interception of radiant energy by the crop canopy and in this respect is analogous to the use of $L$ by Ritchie (1972). 


\section{Materials and methods}

Measurements of evaporation from soil were made at the ICRISAT Sahelian Center, Sadoré, Niger during the rainy season in 1991 and 1993. The sites used in 1991 and 1993 were close to each other and both were within the same area classified as 'Labucheri Sand', a Psammentic Paleustalf (West et al., 1984). Using the FAO soil classification system the soil is a Luvic Arenosol (Swindale, 1982). The soil particle size distribution in the A horizon is typically $91 \%$ sand $(2.0-0.05 \mathrm{~mm}), 5 \%$ silt $(0.05-0.002 \mathrm{~mm})$ and $4 \%$ clay $(<0.002 \mathrm{~mm}$ ) (West et al., 1984). The soil profile is deep (approximately $5 \mathrm{~m}$ ) and there is no water table present.

The climate is dominated by a single rainy season and is typical of the semi-arid tropics. Potential evaporation is high and rainfall erratic at the beginning of the season (see Sivakumar, 1987, or Wallace et al., 1993, for further details). Rainfall for the two years is shown in Fig. 1.

Use of the microlysimeter method in this environment was discussed by Daamen et al. (1993). Briefly, soil cores were extracted within an experimental plot and mounted flush with the soil surface in outsized lining tubes which had been permanently located in undisturbed areas of the plot. In both 1991 and 1993, soil cores were only used to record evaporation from soil for approximately 1 day following the morning of extraction from the soil profile. In both years microlysimeters were $100 \mathrm{~mm}$ deep. Internal diameters were $152 \mathrm{~mm}$ and $51 \mathrm{~mm}$ in 1991 and 1993, respectively. Daamen et al. (1993) reported no significant difference in evaporation recorded using microlysimeters of these two diameters. Microlysimeters were weighed to the nearest $1 \mathrm{~g}$ (1991) or $0.01 \mathrm{~g} \mathrm{(1993).}$

Microlysimeter data were carefully screened to exclude data from soil cores that were older than 1.5 days at the end of the measurement period, and to exclude measurement
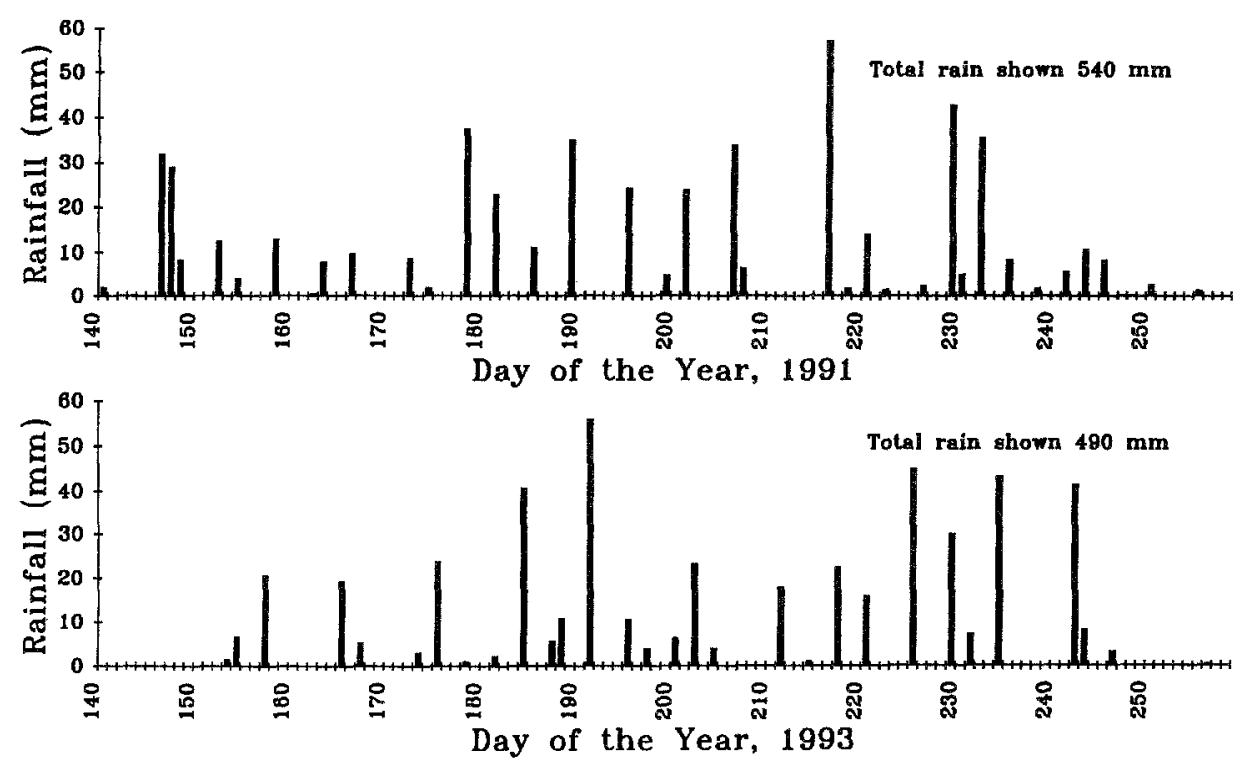

Fig. 1. Daily rainfall at Sadoré, Niger, during the 1991 and 1993 growing seasons. Prior to Day 140, only $45 \mathrm{~mm}$ and $8 \mathrm{~mm}$ fell in 1991 and 1993 respectively. 
periods in which rain fell. This approach minimised the errors inherent in the method allowing differences between cropped and bare plots to be detected reliably (Daamen et al., 1993).

\subsection{Experimental design}

In both years the experimental plots contained two treatments arranged in a randomised block design. The treatment details in the two ycars are given below. Millet is sown in pockets (i.e. holes) which hold 2-3 plants after thinning. Samples for crop growth analysis were taken in four blocks at ten day intervals. Within each plot two millet pockets were taken as a sample. A leaf area meter (LI-COR, Lincoln, NE) was used to determine specific green leaf area of two of the four replicates. Plants were divided into leaves, stems and panicles for dry matter analysis. Leaf area index in the field was calculated from oven-dry leaf weights, specific leaf area, and a count of millet pocket survival.

\section{Trial}

In 1991, $E_{\mathrm{s}}$ was measured in two different crop management systems. The first resembled a traditional crop management system using the following components: flat uncultivated soil; local pearl millet variety (cultivar Sadoré Locale); plants sown on an irregular grid at approximately 6000 pockets ha ${ }^{-1}$ with three plants per pocket after thinning; no applied fertilizer. The improved management system used the following components: ridge/furrow cultivation; improved pearl millet variety (cultivar CIVT); ridges were separated by 0.75 $\mathrm{m}$ and millet sown along the ridge at $1.3 \mathrm{~m}$ spacing giving 10000 pockets ha ${ }^{-1}$ and after thinning three plants per pocket; fertilizer was applied at rates of $45 \mathrm{~kg} \mathrm{~N} \mathrm{ha}^{-1}$ and $45 \mathrm{~kg}$ $\mathrm{P} \mathrm{ha}^{-1}$. Both systems were sown with millet on day of year (Day) 146, 1991. The crops were harvested on Day 239 (improved) and Day 274 (traditional).

Two transects of three microlysimeters were used to measure $E_{\mathrm{s}}$ in the 'Iraditional cropping system. Lining tubes were located at equal distances along the diagonal between two neighbouring millet pockets within one of the replicate blocks. In the improved system, three transects of two microlysimeters were used (one on the ridge and the other beside it in the furrow). The plot size was $10 \mathrm{~m} \times 10 \mathrm{~m}$. Soil cores were extracted from within the plots containing lining tubes or from appropriate plots in neighbouring blocks. Soil cores were taken along transects at the same positions as lining tubes and transects were randomly located within a plot.

\section{Trial}

In 1993 the differences in cropping intensity between the two systems monitored were much larger than in 1991. The millet was flat planted to simplify the measurement of $E_{\mathrm{s}}$. The high density crop system had the following components: improved variety of millet cultivar CIVT (as in 1991); planted on a square grid at 30000 pockets ha $^{-1}$ with three plants per pocket after thinning; fertilizer was applied $\left(30 \mathrm{~kg} \mathrm{P} \mathrm{ha}^{-1} ; 68 \mathrm{~kg} \mathrm{~N} \mathrm{ha}^{-1}\right)$. Evaporation from soil in this high density millet crop was compared with flat bare soil. The millet was suwn un Day 165, and harvested on Day 257. Plot size was $13 \mathrm{~m} \times 13 \mathrm{~m}$.

Use of small-diameter microlysimeters (i.d. $51 \mathrm{~mm}$ ) in 1993 permitted an increased number of replications. $E_{\mathrm{s}}$ measurements were made in three blocks. Four soil cores were 
extracted from the soil profile and mounted within each plot giving a total of 24 microlysimeters for each day of measurement. Soil cores were taken in pairs, one within $0.23 \mathrm{~m}$ of a pocket and the other beside the same pocket but outside this area. The pairs of soil cores were randomly located in the plot.

\subsection{Meteorological and soil water measurements}

Meteorological measurements at the experimental site included rainfall, air temperature, air humidity and windspeed which were averaged over $30 \mathrm{~min}$ intervals in both years. In 1993, net radiation was recorded over the bare soil and the high density cropping treatment. Soil water content was measured using a neutron probe (IH2, Didcot Instrument, Abingdon, UK) at two locations within each high density crop plot and at one location within bare plots in 1993. A field calibration of the neutron probe was carried out at the site for depths $0.1 \mathrm{~m}, 0.2 \mathrm{~m}$ and $0.3 \mathrm{~m}$ or greater. Average profile water contents from $0.05-0.9 \mathrm{~m}$ were determined from six access tubes (i.e. 3 blocks $\times 2$ tubes) in the high density crop and five tubes in bare soil.

Potential evaporation $\left(E_{\mathrm{p}}, \mathrm{mm}\right)$ over a period was taken to be a sum of half-hourly rates, $E_{\mathrm{h}}\left(\mathrm{mm} \mathrm{s}^{-1}\right)$, calculated assuming bare soil conditions as:

$$
\lambda E_{\mathrm{h}}=\frac{\Delta}{\Delta+\gamma}\left(R_{\mathrm{n}}-G_{\mathrm{s}}\right)+\frac{\rho c_{\mathrm{p}}}{\Delta+\gamma}\left(D / r_{\mathrm{a}}\right)
$$

where $\lambda$ is the latent heat of vaporization $\left(\mathrm{J} \mathrm{kg}^{-1}\right), \Delta$ is the slope of saturation vapour pressure verses temperature curve $\left(\mathrm{kPa} \mathrm{K}^{-1}\right), \gamma$ is the psychometric constant $\left(\mathrm{kPa} \mathrm{K}^{-1}\right)$, $\rho c_{\mathrm{p}}$ is the volumetric specific heat of air $\left(\mathrm{J} \mathrm{m}^{-3} \mathrm{~K}^{-1}\right), R_{\mathrm{n}}$ is the net radiation over bare soil (W $\left.\mathrm{m}^{-2}\right), G_{\mathrm{s}}$ is the ground heat flux, positive downward (estimated as $\left.0.2 R_{\mathrm{n}}\right)\left(\mathrm{W} \mathrm{m}^{-2}\right)$, $D$ is the vapour pressure deficit of the air $(\mathrm{kPa})$, see Monteith and Unsworth (1990). The aerodynamic resistance of the atmosphere, $r_{\mathrm{a}}\left(\mathrm{s} \mathrm{m}^{-1}\right)$, was calculated assuming neutral conditions as:

$$
r_{\mathrm{a}}=\frac{\left(\ln \left[(z-d) / z_{0}\right]\right)^{2}}{k^{2} u}
$$

where $z$ is the height of measurement of wind, air temperature and air humidity $(2.5 \mathrm{~m})$, $d$ is the zero plane displacement (insignificant here), $z_{0}$ is the roughness length for the soil surface $(0.01 \mathrm{~m}), k$ is the von Karman constant $(0.41), u$ is the wind speed at height $z$ (m $\left.\mathrm{s}^{-1}\right)$. Calculation of $E_{\mathrm{p}}$ allows comparison of atmospheric demand on bare soil with the measured evaporation during the period. The accuracy of $E_{\mathrm{p}}$ will be affected by the estimate of $G_{\mathrm{s}}$, fetch requirements and air buoyancy effects on $r_{\mathrm{a}}$, however it should still provide a reasonable indication of evaporative demand.

The first term on the right hand side of Eq. 4 is referred to as the radiation term and the second term as the aerodynamic term later in the text.

\section{Results}

Fig. 2 shows the development of green leaf area index $(G)$ in both cropping systems for both years. Differences in $G$ between the two treatments were larger than 0.5 from about Day 193 to 212 in 1991 and from Day 196 to 250 in 1993. 


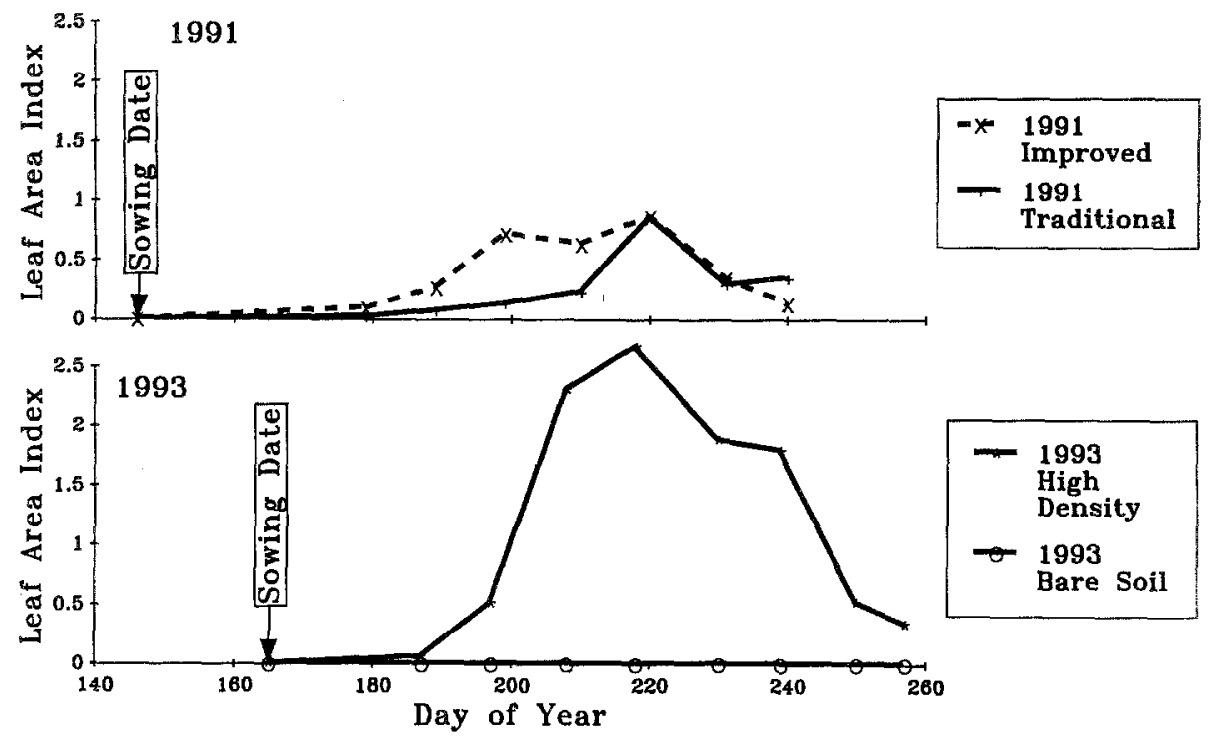

Fig. 2. Green leaf area indices for both treatments in 1991 and 1993.

To test for significant difference in evaporation from soil $\left(E_{\mathrm{s}}\right)$ between treatments in either 1991 or 1993 , analysis of variance in $E_{s}$ data for all measurement days was used. This analysis assumes the data are spatially independent. Lascano and Hatfield (1992) found no spatial structure in $E_{\mathrm{s}}$ data from microlysimeters on flat bare soil down to a separation of 1 m. To achieve homogeneity of variance a square root transformation of $E_{\mathrm{s}}$ data was required in 1991 and a log transformation in 1993 (Lascano and Hatfield, 1992, noted both lognormal and normal distributions of $E_{s}$ ). Also, contrast analysis of the 1991 data revealed that differences between the Traditional system and the Improved system contributed more to the variance than differences between the ridge and the furrow within the Improved system.

Figs. 3 and 4 show the average daily $E_{\mathrm{s}}$ from one treatment plotted against the other for 1991 and 1993, respectively. The difference in treatment means is larger than twice the standard error for points outside the two broken lines drawn on these figures (i.e. they are significantly different at $P=0.05$ ). In both years there was a significant interaction between the effect of the treatment and the measurement date (i.e. the treatment effect was not the same on all days). It is clear from Figs. 3 and 4 that overall the presence of a denser crop (the Improved and the High Density Millet respectively) caused a reduction in evaporation from soil. Cumulative totals of measured evaporation from soil in 1991 and 1993 are presented in Table 1.

Table 2 gives details of the 1993 data set. Green leaf area index of the crop on any particular day was determined by linear interpolation between days of measurement. Similarly, linear interpolation was used to determine the difference in average water content of the bare soil profile $\left(\theta_{b}\right)$ and the cropped profile $\left(\theta_{c}\right)$ from $0.05 \mathrm{~m}$ to $0.90 \mathrm{~m}$. The significance of difference in treatment means is included to show the grouping of significant differences over the season. Details particular to specific days in Table 2 follow: (1) on Days 187 and $191, E_{\mathrm{s}}$ measurements were made in only one of the three blocks; (2) on Day 204 evapo- 


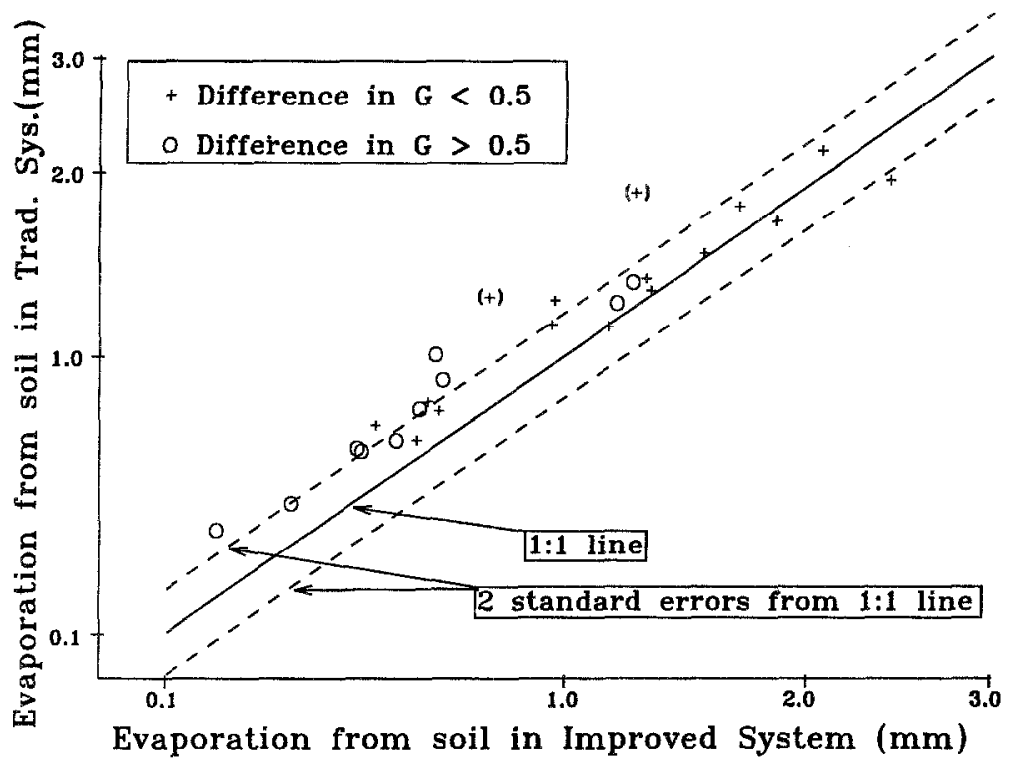

Fig. 3. A comparison of evaporation from soil measured in the improved and in the traditional treatments, 1991. Days of measurement when the difference in green leaf area index $(G)$ values between treatments $>0.5$ are indicated by open circles, days when the difference in $G<0.5$ are indicated by crosses. The two measurement days in parentheses immediately preceded the period in which the difference in $G>0.5$. Points lying outside the bounds of the dashed lines indicate differences in treatment means are significant at the $5 \%$ level.

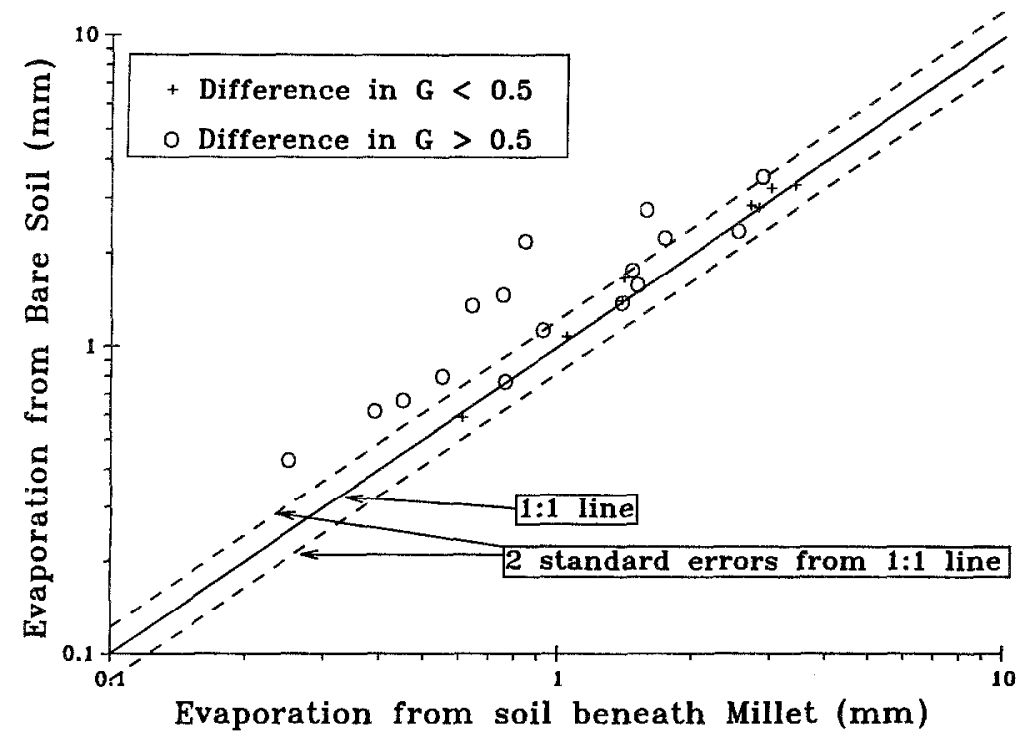

Fig. 4. A comparison of evaporation from soil measured in the Millet and Bare Soil treatments, 1993, excluding data for Day 204 (see text). Symbols and lines are as used in Fig. 3. 
Table 1

Seasonal totals of measured evaporation from soil

\begin{tabular}{llll}
\hline Year/treatment & $\begin{array}{l}\text { Length of period in which } \\
\text { measurements were taken } \\
\text { (days) }\end{array}$ & $\begin{array}{l}\text { Number of days of } \\
\text { measurement }\end{array}$ & $\begin{array}{l}\text { Total measured evaporation } \\
(\mathrm{mm})\end{array}$ \\
\hline 1991 Traditional & 70 & 29 & 34.41 \\
1991 Improved & 70 & 29 & 30.37 \\
1993 Bare Soil & 59 & 25 & 42.79 \\
1993 Millet & 59 & 25 & 35.87 \\
\hline
\end{tabular}

Table 2

Average evaporation from bare and cropped soil for 24 measurement days in 1993. Details of soil, crop and weather conditions for each evaporation period are given, an explanation of how they are calculated is given in the text

\begin{tabular}{|c|c|c|c|c|c|c|c|c|}
\hline $\begin{array}{l}\text { Day of } \\
1993 \\
\text { (days) }\end{array}$ & LAI, $G$ & $\begin{array}{l}\theta_{\mathrm{b}}-\theta_{\mathrm{c}} \\
(\mathrm{mm})\end{array}$ & $\begin{array}{l}\text { Day after } \\
\text { rain } \\
\text { (days) }\end{array}$ & $\begin{array}{l}\text { Preceding } \\
\text { rain }(\mathrm{mm})\end{array}$ & $\begin{array}{l}\text { Potential } \\
\text { evap. } \\
(\mathrm{mm})\end{array}$ & $\begin{array}{l}\text { Evap. } \\
\text { from } \\
\text { bare soil } \\
(\mathrm{mm})\end{array}$ & $\begin{array}{l}\text { Evap. } \\
\text { from } \\
\text { crop soil } \\
\text { (mm) }\end{array}$ & $\begin{array}{l}\text { Significance of } \\
\text { difference }^{\mathrm{a}}\end{array}$ \\
\hline 176 & 0 & 2 & 1 & 24 & - & 2.83 & 2.80 & NS \\
\hline 179 & 0 & $4^{b}$ & 1 & 1 & - & 0.59 & 0.61 & NS \\
\hline 186 & 0 & 2 & 3 & 40 & 5.7 & 1.41 & 1.39 & NS \\
\hline 187 & $0.06^{\mathrm{b}}$ & 2 & 1 & 6 & $4.7^{c}$ & $3.33^{\mathrm{c}}$ & $3.39^{c}$ & NS \\
\hline 189 & 0.1 & $2^{b}$ & 1 & 11 & 6.4 & 3.26 & 2.99 & NS \\
\hline 191 & 0.2 & 2 & 1 & 56 & $1.7^{\mathrm{c}}$ & $1.67^{\mathrm{c}}$ & $1.40^{\mathrm{c}}$ & NS \\
\hline 193 & 0.3 & 2 & 3 & 56 & 6.0 & 1.08 & 1.04 & NS \\
\hline 195 & 0.4 & 4 & 1 & 11 & 4.2 & 2.87 & 2.69 & NS \\
\hline 196 & $0.5^{\mathrm{b}}$ & 5 & 2 & 11 & 4.7 & 1.39 & 1.39 & NS \\
\hline 200 & 0.9 & 9 & 1 & 11 & 5.2 & 3.55 & 2.86 & $*$ \\
\hline 203 & 1.4 & 11 & 1 & 24 & 3.8 & 2.38 & 2.53 & NS \\
\hline 204 & 1.6 & 12 & 2 & 24 & $2.7^{\mathrm{c}}$ & $0.58^{c}$ & $0.97^{\mathrm{c}}$ & $* * *$ \\
\hline 207 & 2.1 & 15 & 4 & 24 & 5.0 & 0.80 & 0.55 & $* *$ \\
\hline 208 & 2.30 & 16 & 5 & 24 & 4.8 & 0.67 & 0.45 & $* * *$ \\
\hline 209 & 2.3 & 17 & 6 & 24 & 3.1 & 0.43 & 0.25 & $* * *$ \\
\hline 215 & 2.6 & 24 & 1 & 2 & 4.5 & 1.13 & 0.92 & $*$ \\
\hline 217 & 2.6 & 25 & 1 & 22 & $1.5^{\mathrm{c}}$ & $1.47^{\mathrm{c}}$ & $0.75^{\mathrm{c}}$ & $* * *$ \\
\hline 218 & 2.66 & 25 & 2 & 22 & 4.1 & 2.26 & 1.73 & $*$ \\
\hline 221 & 2.5 & 25 & 2 & 16 & 4.3 & 1.59 & 1.50 & NS \\
\hline 224 & 2.3 & 25 & 5 & 16 & 3.8 & 0.62 & 0.39 & $* * *$ \\
\hline 228 & 2.0 & 11 & 3 & 46 & 3.7 & 0.77 & 0.76 & NS \\
\hline 230 & 1.84 & 5 & 1 & 30 & 1.7 & 2.20 & 0.84 & $* * *$ \\
\hline 231 & 1.8 & 4 & 1 & 7 & $1.3^{\mathrm{c}}$ & $1.36^{\mathrm{c}}$ & $0.64^{c}$ & $* * *$ \\
\hline 235 & 1.8 & 2 & 2 & 44 & 3.7 & 2.78 & 1.57 & $* * *$ \\
\hline
\end{tabular}

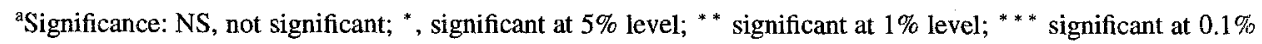
level.

bDay on (or nearest to) day of measurement in bold, other days are estimated by linear interpolation.

'Period over which evaporation from soil was measured was less than 1 day. 
ration was only measured during the middle of the day (10:00-15:30 h) and is likely to be unrepresentative of $E_{\mathrm{s}}$ over the whole day. A greater proportion of daily $E_{\mathrm{s}}$ from a cropped plot is likely to occur around mid-day when the sun is overhead, than from a bare plot in which there is no shading by a canopy, hence the greater value for $E_{s}$.

\section{Discussion}

Fig. 2 shows that green leaf area index did not reach 1.0 in 1991 in contrast with 1993 when the highest leaf area index was 2.66. The plant density in 1993 was three times higher than the improved crop in 1991 and at least three times higher than the local farmers' millet crops. Thus, the data in 1993 should clearly show the potential influence of a crop on $E_{s}$.

The total measured evaporation from soil was reduced in the more intensely-cropped treatments by $12 \%$ and $16 \%$ in 1991 and 1993 respectively (Table 1 ). Although $E_{\mathrm{s}}$ was only measured on about half of the days in the measurement period in either year, the measurement days included a representative selection of 'wet' and 'dry' days. These percentage figures will therefore give an indication of the potential for seasonal reduction in $E_{\mathrm{s}}$ caused by high intensity cropping. In Niger, the seasonal $E_{\mathrm{s}}$ is estimated to account for $40 \%$ of seasonal rainfall (Wallace, 1991) and drainage represents a significant water loss in these soils (Klaij and Vachaud, 1992): hence a $16 \%$ reduction in $E_{\mathrm{s}}$ is not likely to contribute greatly to improved transpiration and crop productivity.

In a dry mediterranean environment (Western Australia), Yunusa et al. (1993b) concluded that sparse canopies of spring wheat had little direct effect on evaporation from soil. They reported only a few light rainfalls after 50 days from sowing. Similarly in northern Syria, Allen (1990) estimated that application of fertilizer resulted in a seasonal reduction in $E_{\mathrm{s}}$ of about $8 \%$ of total evaporation ( $E_{\mathrm{s}}+$ transpiration). Western Australia, Northern Syria and Southern Niger could all be described as semi-arid environments. However, the cropping season of the first two environments begins in a cool wet winter and ends in a dry hot summer while the cropping season in Niger begins in a dry hot season and continues to the end of a wet hot season. In spite of these differences in climate, the effect of a crop on evaporation from the soil was observed to be small and sometimes insignificant. However, it should be noted that a small reduction in $E_{\mathrm{s}}$ achieved through crop management (although difficult to measure) could result in a significant enhancement of transpiration $(T)$ where $T$ is only a small fraction of rainfall and drainage is negligible (e.g. Pilbeam et al., 1995, found $T \approx 0.2^{*}$ rainfall, here a hypothetical reduction of seasonal $E_{\mathrm{s}}$ from $0.8^{*}$ rainfall to $0.75^{*}$ rainfall could result in $T=0.25^{*}$ rainfall, a $25 \%$ increase in transpired water).

The insensitivity of $E_{\mathrm{s}}$ to crop management (e.g. density of cropping and application of fertilizer) and even the presence of a crop, appears to contradict the model of Ritchie (1972) especially in Niger where rainfall is frequent throughout the season and reductions to $E_{\mathrm{s}}$ due to canopy shading would be expected. In these environments this insensitivity suggests that improved management systems are not likely to affect $E_{\mathrm{s}}$ greatly. Also, the insensitivity makes accurate characterisation of the processes governing $E_{\mathrm{s}}$ difficult.

Although the reductions in total evaporation from soil were not largc, the days for which there were significant differences in $E_{\mathrm{s}}$ give information about the processes influencing $E_{\mathrm{s}}$. Differences in $E_{\mathrm{s}}$ between the two treatments were often significant from Day 185 to Day 
213 in 1991 and from Day 207 to Day 235 in 1993. These periods correspond closely to the periods when there was a difference in green leaf area between the treatments. Also, significant differences in $E_{\mathrm{s}}$ were observed on days when $E_{\mathrm{s}}$ was high ( $>=2 \mathrm{~mm}$ ) and when it was low ( $<0.8 \mathrm{~mm}$ ) during these periods (Figs. 3 and 4 ). The most statistically significant differences in $E_{\mathrm{s}}$ occurred at rates of evaporation of about $1 \mathrm{~mm}$ day $^{-1}$ or less (Figs. 3 and 4). Such rates of evaporation would be expected to occur during Ritchie's second stage, in which there is supposed to be no difference between $E_{\mathrm{s}}$ from cropped and bare soil.

In $1993, E_{\mathrm{s}}$ measured for the first whole day after a large rain $(>10 \mathrm{~mm}$ ) was $68 \%$ or less of potential evaporation $E_{\mathrm{p}}$ (Table 2, Days $189,195,200,203$ ), except on Day 230 when $E_{\mathrm{p}}$ was only $1.7 \mathrm{~mm}$. This suggests that a first stage of evaporation does not last for more than several hours after rain on this soil during days with large evaporative demand $\left(E_{\mathrm{p}}>3 \mathrm{~mm}_{\mathrm{day}}{ }^{-1}\right)$. In support of this conclusion, the ratio $\left(E_{\mathrm{s}}\right.$ crop $) /\left(E_{\mathrm{s}}\right.$ bare soil $)$ during the first day after rain was greater than and not equal to the value of $\exp (-0.41 L)$ predicted by Eq. 1 (Table 2, Days 195, 200, 203, 217).

If it is assumed that the first stage of evaporation lasts for 1 day or less, the significant reductions in $E_{\mathrm{s}}$ recorded on Days 207, 208, 209, 218, and 224 in the cropped plot, must have occurred during a second stage of evaporation (Table 2). Significant reductions in $E_{\mathrm{s}}$ during the second stage were also noted in the 1991 season. These reductions contradict Ritchie's hypothesis about the second stage which were discussed earlier. Root uptake of water, which causes differences in profile water content between bare and cropped soil $\left(\theta_{\mathrm{b}}-\theta_{\mathrm{c}}\right)$ will have contributed to this reduction. Shading of the soil surface by the canopy may also contribute during this second stage, especially early in the stage (e.g. Day 235 , Table 2).

The above discussion identifies aspects of the simple $E_{\mathrm{s}}$ models of Ritchie (1972) and Cooper et al. (1983) that do not accord with the measurements. To examine how well the models estimate daily and cumulative evaporation from an initially wet soil profile, outputs from the two models are compared with 1993 field data in Fig. 5. The field data presented are average daily $E_{\mathrm{s}}$ values during a period when the crop was well established (i.e. Days $200,203,207,208,209,218,221,224,228,230,235$, Table 2). Because average $E_{\mathrm{s}}$ values are used the estimates of $E_{\mathrm{s}}$ from the models were determined assuming (1) a constant average value of potential evaporation, $E_{\mathrm{p}}=3.9 \mathrm{~mm}^{-1 a y}{ }^{-1}$ (calculated from all days of field data) and (2) a leaf area index $(L)$ and green leaf area index $(G)$ of 2.0. The original description of the model hy Ritchie (1972) was followed as closely as possible. Bley et al. (1990) estimated values of parameters in the Ritchie model ( $U=3.0 \mathrm{~mm} ; \alpha=2.1 \mathrm{~mm}$ day $^{-1 / 2}$ ) from field measurements made at the ICRISAT Sahelian Center. These values were supported by measurements of $E_{\mathrm{s}}$ from bare soil in 1991 (Daamen, 1993).

Clearly, the application of Ritchie's two-stage model does not provide a good description of the effect of a crop on $E_{\mathrm{s}}$. First stage evaporation apparently persisted for 2 days beneath the crop and only a little more than 1 day on bare soil. An unrealistically large $E_{\mathrm{s}}$ value on the third day after rain (the first whole day of second stage drying) was noted beneath the crop. This may have been the result of a inadequate estimates of $U$ and $\alpha$. However, daily $E_{\mathrm{s}}$ from beneath a crop was larger than that for bare soil and always would be so during the second stage of evaporation in Ritchie's model. 

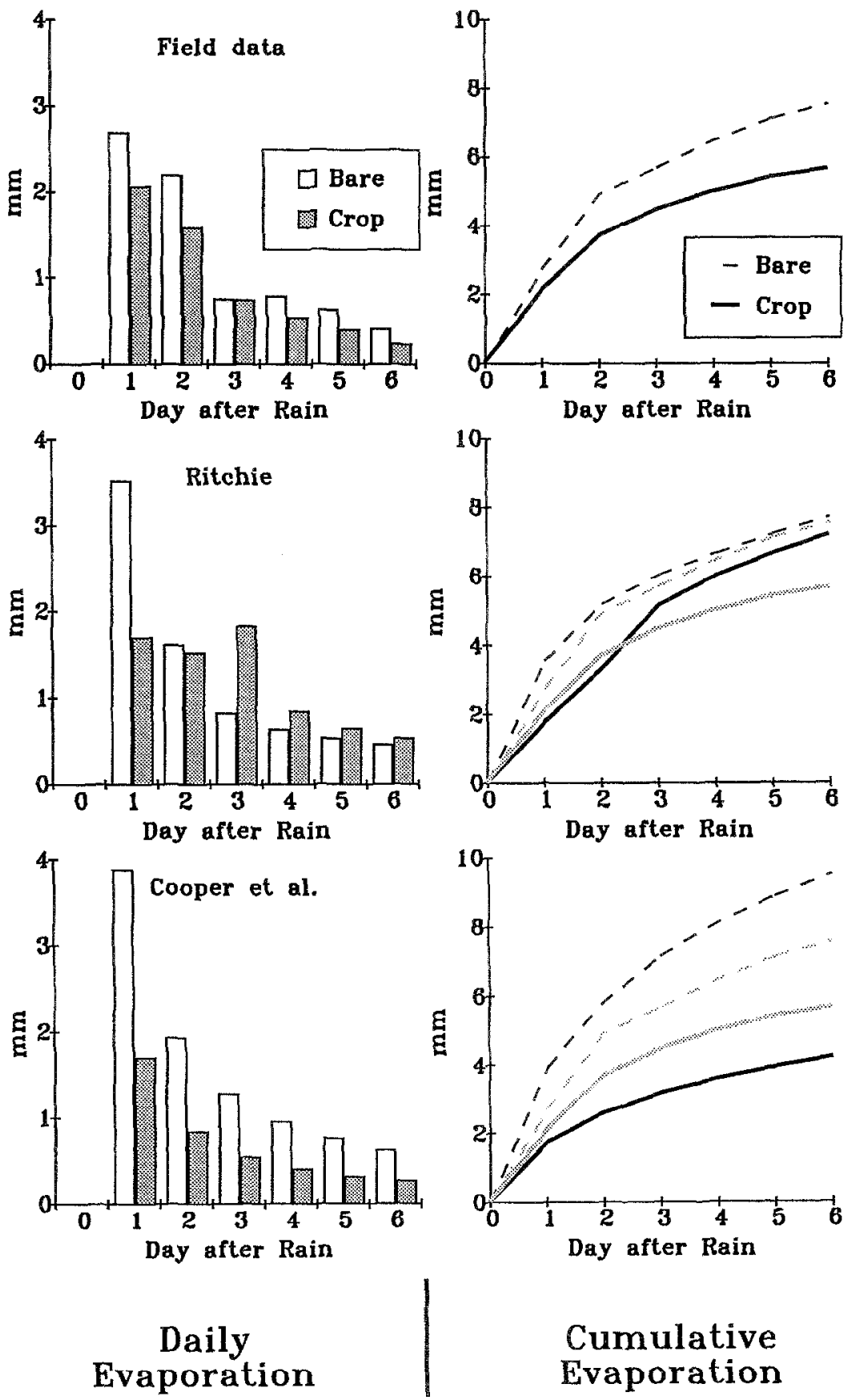

\section{Cumulative Evaporation}

Fig. 5. Daily and cumulative evaporation from bare soil and from soil beneath a crop following an initial wet condition. Field data from Niger in 1993 and estimates of two models (Ritchie, 1972; Cooper et al., 1983) are presented. Cumulative evaporation measured in the field is plotted as lighter lines on the plots with results from the models. 
The model of Cooper et al. (1983) greatly exaggerated the effect of the crop on $E_{\mathrm{s}}$ on all days after rain. Allen (1990) also noted that this model overestimated the reduction in $E_{\mathrm{s}}$ in cropped soil. Cooper et al. consider that the reduction in radiant energy at the soil surface beneath a crop (soil shading) causes a proportional reduction in $E_{\mathrm{s}}$ at all times after rain, giving this large reduction (Fig. 5). (The two-stage model assumes that such a reduction in daily $E_{\mathrm{s}}$ only occurs during first stage.)

In reality, both root water uptake and soil shading can contribute to a reduction of evaporation from soil bencath a crop, but thcy act in different ways. Shading of the soil by a crop canopy effectively reduces evaporative demand, and root water uptake reduces soil profile moisture (thus hydraulic conductivity) thereby restricting water movement to the soil surface. For the environment in Niger we postulate below that root water uptake is the dominant cause of reduced $E_{\mathrm{s}}$ from cropped soil. Exceptions occurred when evaporative demand was low immediately following rain (e.g. Days 230 and 231, Table 2), in which case soil shading was the more likely cause of reduced $E_{\mathrm{s}}$.

\subsection{The effect of root water uptake on $E_{s}$}

If root water uptake is causing a reduction in $E_{\mathrm{s}}$ then this would be the result of lower soil water content in the cropped plots. Indeed, throughout most of the period of significant differences in $E_{\mathrm{s}}$ during the 1993 season, there was a difference in soil profile water content $(5-90 \mathrm{~cm}$ ) between the cropped and bare plots (Table 2). Although evaporation from soil is primarily influenced by soil water contents near the surface (for example $0-10 \mathrm{~cm}$ ), these measurements were not made. Differences in soil water content from $5-90 \mathrm{~cm}$ should provide a good indication of whether root water uptake is likely to have caused differences between cropped and bare plots.

The effect of root water uptake is likely to be largest when differences in green leaf area (i.e. transpiring leaf area) are largest, whereas soil shading is a function of total leaf area irrespective of transpiration. In 1991, significant differences in $E_{\mathrm{s}}$ were observed until Day 213 , but not thereafter. The green leaf area of the two treatments became similar at about this time. However, the improved crop was not harvested until Day 243, and therefore the total leaf area of the improved crop would have been higher than green leaf area between Day 220 and 243, although leaf senescence was occurring. Greater shading of the soil surface by the improved crop during this period appeared to have little influence on $E_{\mathrm{s}}$.

A study on an alfisol in semi-arid India recorded little difference in $E_{\mathrm{s}}$ measured on a bare soil and a bare soil shaded with shade screens (Daamen, 1993). It was concluded that when evaporative demand can not be met by $E_{\mathrm{s}}$ throughout the first day after rain, shading of the soil surface will not effectively reduce $E_{\mathrm{s}}$. In Niger, the evaporative demand is often not met throughout the first day after rain (see Table 2; note also that $U=3$ is less than most daily $E_{\mathrm{p}}$ values). This supports our hypothesis of root water uptake as the dominant cause of $E_{\mathrm{s}}$ reduction. Both Allen (1990) and Yunusa et al. (1993b) recognised root water uptake as an important process influencing $E_{\mathrm{s}}$.

\subsection{Towards an improved model of $E_{s}$ beneath a crop}

Further consideration of processes discussed in the development of the two-stage model of Ritchie (1972) suggests some simple additions which can be made to improve the way 
it accounts for the presence of a crop. The predictions of the Ritchie model differed from field data in two main ways. First, differences in $E_{\mathrm{s}}$ between bare soil and crop are too large on the first day after rain. Second, the model overestimates evaporation from the soil surface of the cropped plot throughout the second stage of evaporation. The causes of these two errors in prediction of $E_{\mathrm{s}}$ are discussed below.

The use of Eq. 1 relies on the assumption that $E_{\mathrm{s}}$ is directly proportional to incident solar radiation (i.e. the aerodynamic term in $\mathrm{Eq} .4$ is assumed to be insignificant). At field sites where meteorological measurements have been made, this assumption is easily checked. It was not found to be accurate at our field site in Niger or by Yunusa et al. (1993b), who reported that the aerodynamic term was twice as large as the radiation term in Eq. 4 for more than half of the season in Western Australia (Despite this, Yunusa et al., 1993b and Yunusa et al., 1993c, continued to use Ritchie's model successfully, perhaps because rainfall events were rare).

If meteorological conditions can only be estimated, or an average seasonal effect is to be modelled then the following approach to accounting for the evaporation due to the aerodynamic term can be used. Assume that the magnitude of the aerodynamic term is a fixed proportion, $W$, of the radiation term. In cases where Ritchie's assumption is valid (e.g. temperate humid climates), $W \approx 0.0$; for the study of Yunusa et al. (1993b) (a hot dry climate), $W=2.0$, for most of the season. This approach to accounting for the aerodynamic term was discussed by Priestley and Taylor (1972) and Jury and Tanner (1975) for wellwatered surfaces. If we also assume that the aerodynamic term is not affected by the presence of a sparse crop, Eq. 6 can be derived and then used in place of Eq. 1 (taking $T_{\mathrm{R}}=$ the radiation term, Eq. 4 can be written as $E_{\mathrm{p}}=T_{\mathrm{R}}(1+W)$ and $E_{\mathrm{pc}}=T_{\mathrm{R}} \exp (-K L)+T_{\mathrm{R}} W$ and elimination of $T_{\mathrm{R}}$ leads to Eq. 6):

$$
E_{\mathrm{pc}}=E_{\mathrm{p}}\left(\frac{\exp (-K L)+W}{1+W}\right)
$$

This treatment effectively reduces the large differences between $E_{\mathrm{s}}$ from a bare soil and beneath a crop on the first day after rain, and it is consistent with current knowledge of evaporation processes.

The second problem with the application of the Ritchie two-stage model was that during second stage evaporation, it was predicting higher $E_{\mathrm{s}}$ from beneath the crop than on the bare soil while measurements showed the reverse to be true. A likely explanation is that the model made no allowance for root uptake of water from the soil.

To take account of root uptake of water, a simple conceptual model of water balance near the soil surface is used, based on the following assumptions which are consistent with earlier work (Daamen et al., 1993). Consider that $E_{\mathrm{s}}$ is the evaporative water loss from a shallow near-surface layer, for example the top $100 \mathrm{~mm}$ of soil. The other water losses from this layer are drainage and root water uptake. No significant upward movement of water occurs at $100 \mathrm{~mm}$ given that the soil has a high sand fraction and that rain events are reasonably frequent during the rainy season. Drainage at $100 \mathrm{~mm}$ is only significant for one or two days after heavy rain and this period coincides with the first stage of evaporation. Also, drainage at 100 Imm following a large rain event will occur in both bare and cropped soil profiles, but root water uptake will occur only in cropped profiles. The initial root water uptake does not cause a difference in water content between a bare and a cropped plot 
because the lack of root water uptake will be compensated for by faster drainage and evaporation in the bare soil profile. However, when drainage ceases, differences will begin to emerge. Using this reasoning, root water uptake is only likely to effect a change in the near-surface water content during second stage evaporation.

Many factors influence root water uptake (e.g. leaf area index, root density distribution, and the distribution of soil water) and obviously a simple model will have to make approximations. Here, the case of a sparse millet crop $(G=2)$ in Niger is considered. As the 0$100 \mathrm{~mm}$ layer dries, both evaporation from the surface and root water uptake from the layer will decrease. These two losses of water are likely to be well correlated because both depend on the matric potential within the layer. As a first approximation, it is assumed that these two losses are proportional throughout second stage evaporation, with a proportionality constant, $V$. This leads to the following approach to modelling evaporation during the second stage. A bare soil profile has only one loss of water, $E_{\mathrm{s},}$, whereas a cropped profile has effectively $(1+V) E_{\mathrm{s}, 2}$ from the surface layer, and hence dries more quickly. The concept that the evaporation rate is inversely proportional to the cumulative loss of water is applied. At the end of each day, cumulative loss from a cropped profile (i.e. the sum of evaporation from soil and root water uptake $\left.\sum(1+V) E_{\mathrm{s}, 2}\right)$ is used to define the "equivalent time into second stage for a bare soil" (denoted $t_{2, \text { eq }}$ in Eq. 7):

$$
t_{2, \mathrm{eq}}=\left(\frac{\sum(1+V) E_{\mathrm{s}, 2}}{\alpha}\right)^{2}
$$

Evaporation from soil for the following day is then calculated as:

$$
E_{\mathrm{s}, 2}=\alpha \sqrt{t_{2, \mathrm{eq}}+1}-\alpha \sqrt{t_{2, \mathrm{eq}}}
$$

Using these corrections to form a new model, the simulated $E_{\mathrm{s}}$ data resembled the observed data much morc closcly (Fig. 6). In addition to the values of $U$ and $\alpha$ already defined, $W$ was set equal to 0.5 after inspection of the meteorological data. $V$ was set equal to 1.0 , which is reasonable given that the green leaf area was 2 and that the millet root density is
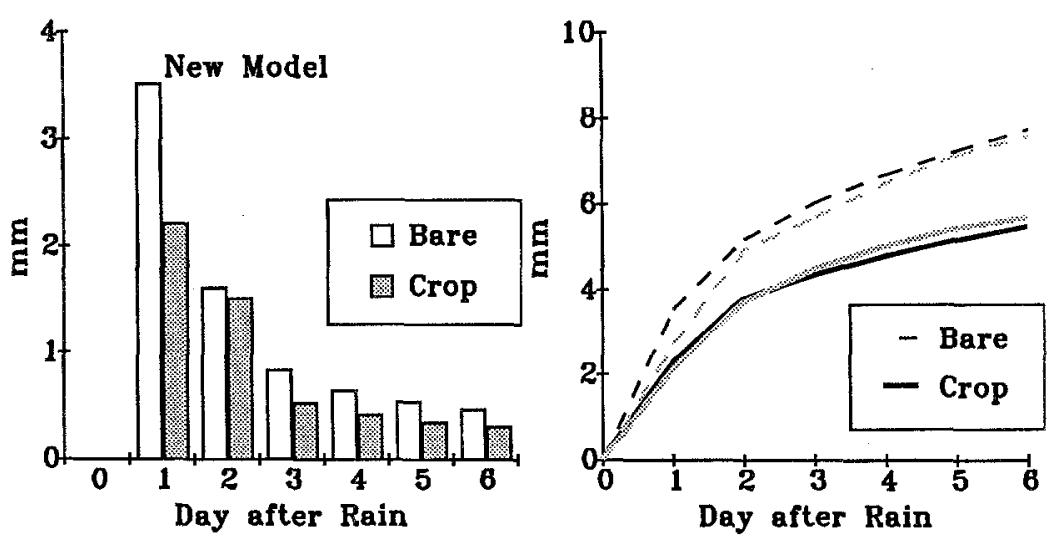

Fig. 6. Estimates of daily and cumulative evaporation from bare soil and from soil beneath a crop using a new model described in the text. Cumulative evaporation measured in the field (from Fig. 5) is plotted as lighter lines on the cumulative evaporation plot. 
at a maximum near the soil surface (Payne et al., 1990; S.R. Gaze, personal communication, 1993). First stage evaporation was assumed to have the same duration beneath a crop as it has on bare soil, using the reasoning (given above) that the water content of the near surface layer follows the same course during the first stage in both bare and cropped soils. The duration of first stage drying was calculated using $U$ and values of $E_{\mathrm{p}}$ estimated using Eq. 4.

The implementation of the model used here is well suited to a sandy soil in an environment with high evaporative demand. It has not yet been applied to other soils and environments. However, the approach used suggests that a crop is likely to be most effective in the reduction of $E_{\mathrm{s}}$ in temperate humid regions (i.e. in conditions where $W \approx 0$ ) and under crops with high leaf areas (i.e. high $V>1$ ). Crops that extract water from the soil near the surface, effectively competing with $E_{\mathrm{s}}$ for soil water, will achieve a greater reduction of $E_{\mathrm{s}}$. The environments of the studies of Yunusa et al. (1993b), Allen (1990), and this study are characterised by high $W$ and low $V$ values and consequently showed little reduction in $E_{\mathrm{s}}$ with the presence of a crop. Irrigated areas of dry regions usually experience large advection and thus have higher values of $W$ (Jury and Tanner, 1975) and a lower potential for reduction of $E_{\mathrm{s}}$.

Some factors will need further consideration before this modification of the two-stage model can be implemented more widely. For example, the influence of potential evaporation during second stage drying, the effect of short first stages of drying ( $<1$ day), and indeed the need for two separate stages of drying must be carefully considered. Also, it should be noted that $W$ and $V$ are by nature variable. However, the constant positive values used here ( $W=0.5, V=1.0$ ) provide a considerable improvement in the estimation of $E_{\mathrm{s}}$ beneath a crop when compared with the approach used by Ritchie (1972) (which effectively used values of $W=0, V=0$ ). Our approach is useful at sites where few measurements are made or in areas where conditions must be estimated. Furthermore it does not rely on any additional theoretical development, it simply applies the approach in a new way.

\section{Acknowledgements}

The authors would like to thank the Natural Resources Institute of the UK Overseas Development Administration for their financial support (EMC X0134). They are also grateful to members of staff at the ICRISAT Sahelian Center, Niamey, for their contributions to this work. This paper was approved for publication as Journal Article JA 1535 of the International Crops Research Institute for the Semi-Arid Tropics (ICRISAT).

\section{References}

Adams, J.E., Arkin, G.F. and Ritchie, J.T., 1976. Influence of row spacing and straw mulch on first stage drying. Soil Sci. Soc. Am. J., 40: 436-442.

Allen, S.J., 1990. Measurement and estimation of evaporation from soil under sparse barley crops in northern Syria. Agric. For. Meteorol., 49: 291-309.

Bley, J., van der Ploeg, R.R. and Sivakumar, M.V.K., 1990. Soil water and nutrient budget studies with millet (Pennisetum americanum L.) in South-West Niger. In: Arbeits- und Ergebnisbericht (Zwischenbericht 1988- 
1990) des Sonderforschungsbereiches 308 "Standortgemäße Landwirtschaft in den Tropen mit Forscungsschwerpunkt Westafrika". University of Hohenheim, Stuttgart, Germany, pp 51-80.

Boast, C.W., 1986. Evaporation from bare soil measured with high spatial resolution, In: A. Klute (Editor), Methods of Soil Analysis, Part 1. Agronomy Monograph No. 9, 2nd Edn., Am. Soc. Agron., Madison, WI, pp 889-900.

Cooper, P.J.M., Keatinge. J.D.H. and Hughes. G., 1983. Crop evapotranspiration-a technique for calculating its components by field measurements. Field Crops Res., 7: 299-312.

Cooper, P.J.M., Gregory, P.J., Tully, D. and Harris, H.C., 1987. Improving water use efficiency of annual crops in the rainfed farming systems of West Asia and North Africa. Expl. Agric., 23: 113-158.

Daamen, C.C., 1993. Evaporation from sandy soils beneath crops in the semi-arid zone. Ph.D. Thesis, University of Reading, UK.

Daamen, C.C., Simmonds, L.P., Wallace, J.S., Laryea K.B. and Sivakumar, M.V.K., 1993. Use of microlysimeters to measure evaporation from sandy soils. Agric. For. Meteorol., 65: 159-173.

Dierckx, J., Belmans, C. and Pauwels, P., 1986. SWATRER a computer package for modelling the field water balance. Laboratory of Soil and Water Engineering, K.U. Leuven, Belgium.

Hanks, R.J. and Ashcroft, G.L., 1980. Applied Soil Physics. Springer, Berlin,

Hillel, D., 1980. Applications of Soil Physics. Academic Press, London, 385 pp.

Jury, W.A., Gardner, W.R. and Gardner, W.H., 1991. Soil Physics (5th edn.). Wiley, New York, 328 pp.

Jury, W.A. and Tanner, C.B., 1975. Advection modification of the Priestley and Taylor evapotranspiration formula. Agron. J., 67: 840-842.

Klaij, M.C. and Vachaud, G., 1992. Seasonal water balance of a sandy soil in Niger cropped with pearl millet, based on profile moisture measurements. Agric. Water Manage., 21: 313-330.

Lascano, R.J. and Hatfield, J.L., 1992. Spatial variability of evaporation along two transects of a bare soil. Soil Sci. Soc. Am. J., 56: 341-346.

Lemon, E.R., 1956. The potentialities for decreasing soil moisture evaporation loss. Soil Sci. Soc. Am. Proc., 20: $120-125$.

Marshall, T.J. and Holmes, J.W., 1988. Soil Physics (2nd edn.). Cambridge University Press.

Monteith, J.L. and Unsworth, M.H., 1990. Principles of Environmental Physics (2nd edn.). Edward Arnold, London, 291 pp.

Papendick, R.I. and Campbell, G.S., 1990. Concepts and management strategies for water conservation in dryland farming. In: P.W. Unger, T.V.Sneed, W.R. Jordan and R. Jensen (Editors), Challenges in Dryland Agriculture. Proc. Int. Conf. on Dryland Farming, August 1988, Amarillo, TX, Texas Agricultural Experiment Station, Bushland, TX, pp. 119-127.

Payne, W.A., Wendt, C.W. and Lascano, R.J., 1990. Root zone water balances of three low-input millet fields in Niger. West Africa. Agron. J., 82: 813-819.

Penman, H.L., 1941. Laboratory experiments on evaporation from fallow soil. J. Agric. Sci., 31: 454-465.

Pilbeam, C.J., Daamen, C.C. and Simmonds, L.P., 1995. Analysis of water budgets in semi arid lands from soil water records. Exp. Agric., 31:131-149.

Priestley, C.H.B. and Taylor, R.J., 1972. On the assessment of surface heat flux and evaporation using large-scale parameters. Monthly Weather Rev., 100: 81-92.

Ritchie, J.T., 1972. Model for predicting evaporation from a row crop with incomplete cover. Water Resourc. Res., 8: 1204-1213.

Shouse, P., Jury, W.A., Stolzy, L.H. and Dasberg, S., 1982. Field measurement and modelling of cowpea water use and yield under stressed and well-watered growth conditions. Hilgardia, 50(6): 1-24.

Sivakumar, M.V.K., 1987. Climate of Niamey. Progress Report-1, ICRISAT Sahelian Center, Niamey, Niger. International Crops Research Institute for the Semi-Arid Tropics, Niamey, Niger.

Swindale, L.D., 1982. Distribution and use of arable soils in the semi-arid tropics. In: Managing Soil Resources, Plenary Session Papers, Trans. 12th Int. Cong. Soil Sci, New Delhi, Int. Soc. Soil Sci., pp. 67-100.

Villalobos, F.J. and Fereres, E., 1990. Evaporation measurements beneath corn, cotton and sunflower canopies. Agron. J., 82: 1153-1159.

Wallace, J.S., 1991. The measurement and modelling of evaporation from semiarid land. In: M.V.K. Sivakumar, J.S. Wallace, C. Renard and C. Giroux (Editors), Soil Water Balance in the Sudano-Sahelian Zone. Proc. Niamey Wotkshop, February 1991, IAHS Publ. No. 199, IAHS, Wallingford, UK, pp. 131-148.

Wallace, J.S., Roberts, J.M. and Sivakumar, M.V.K., 1990. The estimation of transpiration from sparse dryland millet using stomatal conductance and vegetation area indices. Agric. For. Meteorol., 51: 35-49. 
Wallace, J.S., Lloyd, C.R. and Sivakumar, M.V.K., 1993. Measurements of soil, plant and total evaporation from millet in Niger. Agric. For. Meteorol., 63: 149-169.

West, L.T., Wilding, L.P., Landeck, J.K. and Calhoun, F.G., 1984. Soil survey of the ICRISAT Sahelian Center, Niger, West Africa. Soil and Crop Sciences Dept./TropSoils, Texas A\&M University, College Station, TX.

Yunusa, I.A.M., Belford, R.K., Tennant, D. and Sedgley, R.H., 1993a. Row spacing fails to modify soil evaporation and grain yield in spring wheat in a dry mediterranean environment. Aust. J. Agric. Res., 44: 661-76.

Yunusa, I.A.M., Sedgley, R.H., Belford, R.K. and Tennant, D., 1993b. Dynamics of water use in a dry mediterranean environment: 1 Soil evaporation little affected by presence of plant canopy. Agric. Water Manage., 24: 205-224.

Yunusa, I.A.M., Sedgley, R.H., Tennant, D. and Belford, R.K., 1993c. Dynamics of water use in a dry mediterranean environment: 2 A test of four evaporation models using microlysimetry under spring wheat. Agric. Water Manage., 24: 225-238. 